\title{
The effects of catastrophic drug plan deductibles on older women's use of cardiovascular medicines: a retrospective cohort study
}

\author{
Steven G. Morgan PhD, Emilie J. Gladstone MPH, Deirdre Weymann MA, Nadia Khan MSc MD
}

Abstract

Background: In recent years, some provinces have implemented income-based catastrophic drug coverage in an effort to provide universal drug coverage while limiting government liability for the escalating costs of medicines needed for an aging population. We sought to examine the effects of income-based deductibles under British Columbia's Fair PharmaCare system on older patients' use of cardiovascular medicines in 2013, 10 years after the province's policy change.

Methods: Using linked administrative databases, we studied rates of hypertension and cholesterol medication used by 2 cohorts of older, married women who had different levels of public drug subsidy based solely on their spouses' ages. We compare measures of 2013 medication use by study cohorts using statistical models that controlled for age, general health status, indicators of need for specific drug classes, ethnicity, rural residence and household income.

Results: Among members of our study cohorts, the odds of filling cardiovascular prescriptions in 2013 were influenced by patient age, general health status, drug-specific diagnoses, ethnicity, place of residence and household income. For women with household incomes less than $\$ 50000$ (42\% of our study population), having preferential public drug coverage by way of spousal age was associated with a $15 \%$ increase in the adjusted odds of filling 1 or more prescription for hypertension treatment (adjusted odds ratio [OR] $1.15,95 \%$ confidence interval $[\mathrm{Cl}] 1.06$ to 1.24 ) and a $13 \%$ increase in the adjusted odds of filling 1 or more prescription for cholesterol treatments (adjusted OR $1.13,95 \% \mathrm{Cl} 1.06$ to 1.21). There were no statistically significant effects on the number of days of therapy purchased per user of these cardiovascular medicines.

Interpretation: We have found that the level of income-based deductibles under catastrophic drug benefi t plans can affect the use of cardiovascular drug treatments, even long after deductibles are put in place. These results add to the body of evidence in support of the idea that public drug coverage design can affect access to necessary medications.

$\mathrm{P}$ ublic drug coverage in many Canadian provinces initially evolved as a form of targeted benefit for society's more vulnerable population subgroups, such as the poor and the elderly. ${ }^{1}$ In recent years, however, some provinces have implemented income-based catastrophic drug coverage in an effort to provide at least some form of universal drug coverage while limiting government liability for escalating costs of medicines needed for an aging population. ${ }^{2}$

Under income-based catastrophic drug coverage plans, households must privately finance the cost of medications under deductibles that are set as a percentage of household income; the percentages of incomes that define the deductibles under these plans range from $3 \%$ to $10 \%$ for median household incomes across provinces that offer such benefits. ${ }^{3}$ Households then must privately finance a proportion of drug costs beyond deductibles by way of paying for the coinsurance on additional prescriptions in the year; coinsurance rates are defined as a percentage of drug costs, which vary across provinces and can differ by income level. ${ }^{3}$

To date, the largest province to adopt a universal, incomebased catastrophic drug plan is British Columbia. It implemented its program, "Fair PharmaCare," in 2003. ${ }^{4}$ Before this date, the British Columbia "PharmaCare" program was an agebased public drug plan in the sense that, in addition to providing complete coverage of medicines for social assistance recipients of all ages, the public plan also covered virtually all drug costs, without deductibles, for people over 65 years of age. ${ }^{5}$

Competing interests: None declared.

This article has been peer reviewed.

Correspondence to: Steven Morgan, steve.morgan@ubc.ca

CMAJ Open 2017. DOI:10.9778/cmajo.20160145 
To ease the transition from age-based to income-based drug coverage, the Fair PharmaCare program provided more comprehensive coverage for households with 1 or more family member born in 1939 or earlier - see Table 1. Policymakers hoped the enhanced terms of coverage for older patients at the time of the policy change would prevent adverse drug use responses - and political pressures - stemming from the implementation of deductibles for older patients who were previously entitled to comprehensive public drug coverage. ${ }^{6}$

Despite efforts to mitigate the effects of the change in benefits, the implementation of Fair PharmaCare was shown to have reduced treatment adherence among older patients with respiratory disease, depression and those who experienced myocardial infarction..$^{7-10}$ More recent research has shown that British Columbians reported cost-related nonadherence to prescribed therapies more frequently than residents of other provinces. ${ }^{11,12}$ It has been difficult to ascertain whether the more recent perceptions of barriers to accessing medications in British Columbia are the sustained effect of the move to an income-based policy more than 10 years ago or the result of other influences on medication accessibility, such as relatively high housing costs.

In this study, we examine the effects of the income-based deductibles under British Columbia's Fair PharmaCare system on older patients' use of cardiovascular medicines in 2013, 10 years after the policy change. We use the household-level at which public drug coverage was offered to older British Columbians as a form of natural experiment. Specifically, we compare use of prescription drugs by 2 groups of married women born from 1940 to 1944: the first group comprised those who qualified for enhanced Fair PharmaCare coverage solely because their spouses were born in 1939 or earlier; the second group comprised married women of the same age who did not qualify for enhanced assistance because their spouses were born after 1939. The women with enhanced assistance by way of marriage faced lower deductibles and coinsurance levels than those who received standard assistance.

\section{Methods}

\section{Study design and setting}

This is a retrospective study of outpatient prescription drug dispensations to older British Columbians during 2013. All residents of British Columbia are covered under a universal, public health insurance program for medically necessary physicians' services and hospital care, including prescription drugs used in hospital, without direct cost to the patient. Residents are also eligible for pharmaceutical coverage under British Columbia's universal, income-based public drug benefit plan, Fair PharmaCare.

\section{Data sources and cohort}

We obtained deidentified linked health data sets from Population Data BC. ${ }^{13-15}$ The data sets included sociodemographic information and records of all prescription drug dispensations, fee-for-service physician visits, and admissions to hospital for all study participants during 2013. Our data on prescription drug purchases came from BC PharmaNet, which includes records of every prescription dispensed outside of acute care hospitals regardless of how the prescription was financed. These data sets excluded military veterans, registered First Nations and inmates of federal penitentiaries (4\% of the population, combined).

Our study cohort included all women born in the 5-year period from 1940 to 1944 who were married (not widowed) at the start of 2013 and who were alive and resided in British Columbia for at least 275 days in the year. Because of their own age, these women would not qualify for enhanced Fair PharmaCare assistance if they were unmarried: they were all born after 1939. However, among these women, those with spouses born in 1939 or earlier were eligible for enhanced Fair PharmaCare assistance, while those with spouses born in 1940 or later were eligible for standard Fair PharmaCare assistance. Because too few men (about 3100, or 5\% of married men born from 1940 to 1944) qualified for enhanced PharmaCare assistance by way of marriage to older spouses, we were unable to conduct equivalent analyses for married men of the same generation.

Table 1: Terms of enhanced and standard Fair PharmaCare assistance

\begin{tabular}{|c|c|c|c|}
\hline Household income, \$ & $\begin{array}{l}\text { Deductible, as percentage of } \\
\text { household income, \% }\end{array}$ & $\begin{array}{c}\text { Coinsurance paid by } \\
\text { household after deductible is } \\
\text { reached, \% }\end{array}$ & $\begin{array}{l}\text { Threshold beyond which } \\
\text { government pays all drug } \\
\text { costs as percentage of } \\
\text { household income, \% }\end{array}$ \\
\hline \multicolumn{4}{|c|}{ Enhanced assistance for households with 1 or more member born in 1939 or earlier } \\
\hline Less than 33000 & 0 & 25 & 1.25 \\
\hline $33000-50000$ & 1 & 25 & 2 \\
\hline Over $\$ 50000$ & 2 & 25 & 3 \\
\hline \multicolumn{4}{|c|}{ Standard assistance for all other households } \\
\hline Less than 15000 & 0 & 30 & 2 \\
\hline $15000-30000$ & 2 & 30 & 3 \\
\hline Over 30000 & 3 & 30 & 4 \\
\hline
\end{tabular}


Data sets contained no information about whether women had private insurance for drug costs not paid for by the PharmaCare program. Those costs are simply identified as private expenditure on dispensed prescriptions, whether paid for outof-pocket or through voluntary private insurance.

Administrative data sets contained a primary diagnostic code (International Classification of Diseases, 10th revision [ICD-10]) for every fee-for-service medical visit, and up to 25 diagnostic codes for each record of an acute care hospital admission (including day procedures). To ensure complete and comparable capture of available diagnostic information, we excluded patients who lived in geographic areas that receive $25 \%$ or more of their medical care from non-fee-forservice providers ( $<4 \%$ of the population). We also excluded residents of long-term care facilities and all recipients of social assistance because these individuals have unique health care needs and receive benefits under specific PharmaCare programs that do not involve deductibles. Finally, we excluded people who spent the more than half the year, 183 days, in an acute care hospital (where drug costs are fully covered but not entered into available databases) because there would be incomplete prescription drug use data for such patients.

\section{Variables}

Using drug identification codes in the data sets, we identified all prescriptions for antihypertensive agents and cholesterol medications - details in Appendix 1 (available at www.cmajopen.ca/ content/5/1/E198/suppl/DC1). Our primary outcome variables were 2 measures of the use of medications within each drug class during calendar year 2013. The first was a period prevalence measure of exposure: whether or not a participant filled 1 or more prescription from the relevant drug class during 2013. The second was a measure of the quantity of relevant treatments used during the 2013 period: the number of days of therapy purchased over the course of the year among participants who filled 1 or more prescription from the relevant drug class. Though this latter measure is similar to common adherence measures, it should be interpreted as adherence among prevalent users, not just new users, of the treatments.

For each patient, we searched all medical and hospital records for 2013 to find diagnoses related to indicated uses for each drug class studied. For regression analyses, we grouped relevant diagnoses into Expanded Diagnostic Clusters of the Johns Hopkins Adjusted Clinical Groups case-mix adjustment system (version 10.0) - details in Appendix 2 available at www.cmajopen.ca/content/5/1/E198/suppl/DC1.

Also using the diagnoses in all medical and hospital records for 2013, we gauged overall health status based on counts of major Aggregated Diagnostic Groups (ADGs) of the Johns Hopkins Adjusted Clinical Groups case-mix adjustment system. This approach to risk-adjustment for general health status has been validated for studying pharmaceutical use in British Columbia. ${ }^{16}$

Owing to high rates of participation in the income-based drug plan among older British Columbians, our data sets contained validated household-specific income information for $94 \%$ of our study population. ${ }^{17}$ The remaining $6 \%$ of study participants had not applied for coverage under the Fair PharmaCare program, perhaps because of lack of awareness or lack of need for the subsidy. ${ }^{18} \mathrm{We}$ assigned these participants incomes based on the average taxable income per household in the neighbourhood in which they lived. ${ }^{17} \mathrm{We}$ also assigned them to the level of Fair PharmaCare coverage they would have qualified for based on the age of their spouse (as these women's ages alone would qualify them all for standard assistance).

We assigned patients to ethnic groups using a validated algorithm to identify surnames of the dominant ethnic minorities in British Columbia: Chinese (40\% of minorities) and South Asians (26\% of minorities). ${ }^{19,20}$ Finally, we categorized neighbourhood urbanization based on the population density of the Local Health Area in which people lived.

\section{Statistical analyses}

We calculated population characteristics for the cohorts of women who qualified for either standard Fair PharmaCare or enhanced Fair PharmaCare assistance based on their spouse's age. We estimated logistic regressions of binary, period prevalence measures of drug use: use being defined as filling 1 or more relevant prescription in 2013. For the subset of users of each class of medicines, we estimated linear regressions of a continuous use measure: the number of days of therapy dispensed to patients over the year.

Our primary objective was to compare use measures across enhanced versus standard Fair PharmaCare assistance. Differences in enhanced versus standard assistance levels are greatest at income levels below $\$ 50000$. Therefore, we tested for the effect of enhanced assistance below and equal or above $\$ 50000$ using separate dummy variables for these ranges of income.

After testing for collinearity between explanatory variables and comparing goodness of fit across models, our final models controlled for age, general health status, individual indicators of need for specific drug classes, ethnicity, level of neighbourhood urbanization and enhanced assistance for pharmacare. We ran sensitivity analyses on samples stratified by income levels (above and below \$50 000) and on different specifications of income levels and enhanced assistance. For all analyses, a value of $p$ less than 0.05 was considered significant. All analyses were performed using Stata version 13.1 and SAS version 9.3 .

\section{Ethics approval}

We received approval from the relevant data stewards and the University of British Columbia's Behavioural Research Ethics Board.

\section{Results}

A total of 53285 women met our study inclusion criteria, 53\% of whom qualified for enhanced assistance under the Fair PharmaCare program by way of their spouse's age. Table 2 lists the characteristics of the study cohort, stratified by assistance level. Despite both groups comprising patients born in the same 5-year period (1940 to 1944), women who qualified 


\begin{tabular}{|c|c|c|}
\hline Characteristic & $\begin{array}{c}\text { Standard } \\
\text { assistance, \%* } \\
n=28539\end{array}$ & $\begin{array}{c}\text { Enhanced } \\
\text { assistance, \%* } \\
n=24926\end{array}$ \\
\hline \multicolumn{3}{|l|}{ Age $^{*}, \mathrm{yr}$} \\
\hline 69 & $8961(31.6)$ & 3315 (13.3) \\
\hline 70 & $7458(26.3)$ & $4212(16.9)$ \\
\hline 71 & $5615(19.8)$ & $5085(20.4)$ \\
\hline 72 & $3828(13.5)$ & $5708(22.9)$ \\
\hline 73 & $2496(8.8)$ & $6605(26.5)$ \\
\hline \multicolumn{3}{|l|}{ Health status } \\
\hline 1-2 major ADGs & $12421(43.8)$ & $11167(44.8)$ \\
\hline$\geq 3$ major ADGs & $1957(6.9)$ & $1919(7.7)$ \\
\hline \multicolumn{3}{|c|}{$\geq 1$ diagnoses of primary indications $†$} \\
\hline Antihypertensives & $16618(58.6)$ & 15529 (62.3) \\
\hline Cholesterol drugs & $5615(19.8)$ & $5284(21.2)$ \\
\hline \multicolumn{3}{|l|}{ Incomet, \$ } \\
\hline 0-14999 & $709(2.5)$ & $698(2.8)$ \\
\hline 15 000-29 999 & $3148(11.1)$ & $3963(15.9)$ \\
\hline 30 000-32 999 & $567(2.0)$ & $1371(5.5)$ \\
\hline $33000-42999$ & $3290(11.6)$ & $3614(14.5)$ \\
\hline $43000-49999$ & $2439(8.6)$ & $2642(10.6)$ \\
\hline $50000-56999$ & $3431(12.1)$ & $2418(9.7)$ \\
\hline $57000-69999$ & $4197(14.8)$ & $2767(11.1)$ \\
\hline$\geq 70000$ & $10550(37.2)$ & $7478(30.0)$ \\
\hline \multicolumn{3}{|l|}{ Fair PharmaCare† } \\
\hline Registered for plan & 25835 (91.1) & $23929(96.0)$ \\
\hline \multicolumn{3}{|l|}{ Ethnicity† } \\
\hline Chinese & $1730(6.1)$ & $2817(11.3)$ \\
\hline South Asian & $116394.1)$ & $997(4.0)$ \\
\hline \multicolumn{3}{|l|}{ Rural dwelling } \\
\hline Rural & $2297(8.1)$ & $2044(8.2)$ \\
\hline \multicolumn{3}{|l|}{ Overall health care use } \\
\hline $\begin{array}{l}\text { Mean total cost of } \\
\text { medical care, } \$\end{array}$ & 1112 & 1167 \\
\hline $\begin{array}{l}\text { Mean no. of medical care } \\
\text { visits }\end{array}$ & 16.8 & 17.7 \\
\hline $\begin{array}{l}\text { Mean total cost of } \\
\text { hospital care, } \$\end{array}$ & 1067 & 1112 \\
\hline $\begin{array}{l}\text { Share with } 1 \text { or more } \\
\text { admissions to hospital, } \\
\text { no. }(\%)\end{array}$ & $6267(22.1)$ & $5558(22.3)$ \\
\hline $\begin{array}{l}\text { Note: } A D G=\text { aggregated diagnostic } \\
\text { *Unless otherwise indicated. } \\
\text { †Difference significant at } p=0.05 \text {. }\end{array}$ & & \\
\hline
\end{tabular}

for enhanced assistance under the Fair PharmaCare program were slightly older than women receiving standard assistance (mean age 70.4 v. $71.3 \mathrm{yr}$ ). We expected this because women who received enhanced benefits had to be married to older spouses (born in 1939 or earlier) than women receiving standard benefits.

Likely reflecting the differences in age across study subgroups, a slightly larger proportion of the women who qualified for enhanced assistance had 3 or more major comorbidities compared with women who received standard assistance $(6.9 \%$ v. $7.7 \%)$. A slightly larger proportion of enhanced benefit recipients had 1 or more diagnoses of conditions for which antihypertensive agents or statins are primarily indicated. Enhanced benefit recipients were also more likely to have lower family income, and to have registered for the public drug plan. Women who qualified for enhanced assistance were also more likely to have a Chinese surname, which reflects greater mean differences in spouses' age among Asian couples. ${ }^{21}$ There were no significant differences between beneficiary groups in terms of overall use of medical or hospital care.

Table 3 lists detailed results from regression analyses for the drug classes of interest: antihypertensive drugs and cholesterol drugs. There was an age gradient in the period prevalence of exposure to antihypertensive agents and cholesterol drugs in our study cohort, as expected, with older participants being more likely to fill prescriptions for these medications than younger participants. Patients with worse overall health status, as measured by higher counts of major ADGs, were also more likely to fill antihypertensive and cholesterol prescriptions. Patients with specific diagnosed illnesses for which antihypertensive and cholesterol treatments are indicated had greater odds of filling relevant prescriptions. When compared with exposure to therapy, age and health status had similar, though fewer significant effects on the mean duration of therapy used per patient filling 1 or more prescription for antihypertensive or cholesterol drugs.

Patient ethnicity had some significant effects on the use of the cardiovascular medicines studied. After controlling for other factors, the model found women of Chinese ethnicity to be less likely to fill 1 or more prescription for antihypertensive agents (adjusted odds ratio [OR] 0.63, 95\% confidence interval [CI] 0.57 to 0.69 ), but more likely to fill 1 or more prescription for cholesterol drugs (adjusted OR 1.24, 95\% CI 1.14 to 1.34$)$. Chinese women who filled 1 or more prescription for hypertension purchased fewer overall days of antihypertensive agents than other women $(\beta=-49.5,95 \%$ CI -64 to -35$)$. South Asian women were also less likely to fill 1 or more prescription for antihypertensive agents (adjusted OR $0.83,95 \%$ CI 0.73 to 0.94 ) and more likely to fill 1 or more prescription for cholesterol drugs (adjusted OR 1.44, 95\% CI 1.30 to 1.60$)$. South Asian women who filled 1 or more cholesterol prescription purchased fewer days of those treatments than other women $(\beta=-17.4,95 \% \mathrm{CI}-27.4$ to -7.3$)$.

After controlling for other factors in the model, we found income had no significant effects on the likelihood that women in our study filled 1 or more prescription for hyper- 


\section{OPEN}

Research

Table 3: Adjusted odds ratios for the likelihood of filling at least 1 prescription and adjusted difference in days of therapy per person filling at least 1 prescription for antihypertensive and cholesterol treatments

\begin{tabular}{|c|c|c|c|c|}
\hline \multirow[b]{2}{*}{ Characteristic } & \multicolumn{2}{|c|}{ Exposure to treatment } & \multicolumn{2}{|c|}{ Duration of treatment } \\
\hline & $\begin{array}{c}\text { Antihypertensive } \\
\text { agents } \\
\text { Adjusted OR }(95 \% \mathrm{Cl})\end{array}$ & $\begin{array}{l}\text { Cholesterol treatments } \\
\text { Adjusted OR }(95 \% \mathrm{Cl})\end{array}$ & $\begin{array}{c}\text { Antihypertensive } \\
\text { agents } \\
\beta(95 \% \mathrm{Cl})\end{array}$ & $\begin{array}{c}\text { Cholesterol treatments } \\
\beta(95 \% \mathrm{Cl})\end{array}$ \\
\hline \multicolumn{5}{|l|}{ Age (69 = reference), yr } \\
\hline 70 & $1.01(0.94$ to 1.08$)$ & $1.10(1.03$ to 1.17$)$ & $2.1(-9.1$ to 13.3$)$ & $-0.7(-7.7$ to 6.2$)$ \\
\hline 71 & $1.15(1.07$ to 1.24$)$ & $1.10(1.03$ to 1.18$)$ & $9.1(-2.2$ to 20.5$)$ & $-3.5(-10.5$ to 3.6$)$ \\
\hline 72 & $1.14(1.06$ to 1.24$)$ & 1.14 (1.06 to 1.22$)$ & 17.6 (5.9 to 29.4$)$ & $-2.1(-9.4$ to 5.2$)$ \\
\hline 73 & 1.19 (1.10 to 1.29$)$ & $1.19(1.11$ to 1.28$)$ & 14.5 (2.5 to 26.5$)$ & $-2.1(-9.5$ to 5.3$)$ \\
\hline \multicolumn{5}{|c|}{ Health: no. of major ADGs ( 0 = reference) } \\
\hline 1 to 2 & $1.30(1.23$ to 1.37$)$ & $1.26(1.20$ to 1.32$)$ & 14.7 (6.5 to 22.8$)$ & $4.7(-0.5$ to 9.8$)$ \\
\hline$\geq 3$ & $1.34(1.21$ to 1.49$)$ & 1.39 (1.28 to 1.52$)$ & $-1.4(-15.2$ to 12.5$)$ & $-5.6(-14$ to 2.7$)$ \\
\hline \multicolumn{5}{|c|}{ Diagnoses of specific indications, EDC codes } \\
\hline CAR14 or CAR15: Hypertension & 27.25 (25.86 to 28.72$)$ & & 90.3 (81.2 to 99.3$)$ & \\
\hline $\begin{array}{l}\text { CAR01: cardiovascular signs and } \\
\text { symptoms }\end{array}$ & $1.36(1.28$ to 1.46$)$ & & $6.7(-2.3$ to 15.6$)$ & \\
\hline CAR05: Congestive heart failure & 5.25 (4.35 to 6.35$)$ & & 66.5 (48.9 to 84.2$)$ & \\
\hline CAR07: Cardiomyopathy & 11.62 (5.73 to 23.56$)$ & & 48.5 (5.8 to 91.2$)$ & \\
\hline END06 or END07: type 1 diabetes & 13.24 (5.42 to 32.3$)$ & & 210.5 (111 to 309.9$)$ & \\
\hline END08 or END09: type 2 diabetes & $6.9(6.46$ to 7.38$)$ & & 117.9 (109.4 to 126.4$)$ & \\
\hline CAR03: Ischemic heart disease & 2.59 (2.34 to 2.87 ) & 2.68 (2.49 to 2.87$)$ & 60.9 (49.4 to 72.4$)$ & $10.6(4.2$ to 17.1$)$ \\
\hline CAR10: Generalized atherosclerosis & 2.06 (1.54 to 2.76$)$ & 2.08 (1.7 to 2.54$)$ & $61.1(29.5$ to 92.7$)$ & $15.6(-0.8$ to 31.9$)$ \\
\hline CAR12: Acute myocardial infarction & 3.39 (2.01 to 5.7$)$ & 2.62 (2.03 to 3.38$)$ & $-21(-56.4$ to 14.4$)$ & $-54.6(-72.4$ to -36.9$)$ \\
\hline CAR11: Disorders of lipoid metabolism & & 3.21 (3.02 to 3.4$)$ & & $-20.6(-26.1$ to -15.2$)$ \\
\hline NUR05: Cerebrovascular disease & & 2.3 (2.07 to 2.55$)$ & & $-3.1(-12.2$ to 6.01$)$ \\
\hline \multicolumn{5}{|l|}{ Ethnicity (white/other = reference) } \\
\hline Chinese & $0.63(0.57$ to 0.69$)$ & $1.24(1.14$ to 1.34$)$ & $-49.5(-64$ to -35$)$ & $-3.2(-11.4$ to 5$)$ \\
\hline South Asian & $0.83(0.73$ to 0.94$)$ & $1.44(1.30$ to 1.60$)$ & $-10.9(-28.6$ to 6.8$)$ & $-17.4(-27.4$ to -7.3$)$ \\
\hline \multicolumn{5}{|l|}{ Setting (urban/suburban = reference) } \\
\hline Rural setting & $1.10(1.01$ to 1.21$)$ & 0.94 (0.86 to 1.02$)$ & $6.6(-6.6$ to 19.7$)$ & $-0.4(-8.9$ to 8.2$)$ \\
\hline \multicolumn{5}{|l|}{ Income ( $<15000=$ reference), $\$$} \\
\hline 15 000-29 999 & $1.01(0.86$ to 1.20$)$ & 1.19 (1.03 to 1.37$)$ & $34.4(10.6$ to 58.2$)$ & $5.6(-8.7$ to 19.9$)$ \\
\hline $30000-32999$ & 0.89 (0.73 to 1.09$)$ & 1.15 (0.97 to 1.37$)$ & 47.5 (18.5 to 76.4$)$ & $-0.4(-17.8$ to 17$)$ \\
\hline 33 000-42999 & 0.99 (0.83 to 1.17$)$ & $1.12(0.97$ to 1.30$)$ & $52.6(28.0$ to 77.1$)$ & $11.7(-3.0$ to 26.5$)$ \\
\hline $43000-49999$ & $0.96(0.81$ to 1.15$)$ & $1.05(0.90$ to 1.23$)$ & 46.6 (21.2 to 72.0$)$ & $12.5(-2.8$ to 27.8$)$ \\
\hline $50000-56999$ & $1.00(0.83$ to 1.19$)$ & $1.11(0.95$ to 1.30$)$ & 44.8 (18.8 to 70.8$)$ & 17.6 (2.0 to 33.3$)$ \\
\hline $57000-69999$ & $1.02(0.86$ to 1.22$)$ & $0.96(0.82$ to 1.13$)$ & 40.6 (14.8 to 66.4$)$ & 19.3 (3.7 to 34.9$)$ \\
\hline$\geq 70000$ & $0.93(0.78$ to 1.10$)$ & $0.89(0.77$ to 1.03$)$ & $35.5(10.9$ to 60.1$)$ & 23.6 (8.8 to 38.4$)$ \\
\hline \multicolumn{5}{|c|}{ PharmaCare assistance (standard = reference), \$ } \\
\hline Enhanced, $<50000$ & 1.15 (1.06 to 1.24$)$ & $1.13(1.06$ to 1.21$)$ & $7.5(-3.6$ to 18.7$)$ & $6.1(-0.7$ to 12.8$)$ \\
\hline Enhanced, > 50000 & 0.98 (0.91 to 1.04$)$ & $1.08(1.01$ to 1.15$)$ & $4.1(-6.2$ to 14.5$)$ & $-0.3(-6.7$ to 6.2$)$ \\
\hline
\end{tabular}


tension treatments. Income also had limited significant effects on the likelihood of filling 1 or more prescription for cholesterol drugs. Higher incomes were associated with greater adjusted mean number of days of antihypertensive and cholesterol therapy purchased among those filling 1 or more prescription for either of those types of therapy.

Enhanced assistance under the Fair PharmaCare program had significant effects on the likelihood of filling 1 or more prescription for antihypertensive and cholesterol drugs. After controlling for other health and socioeconomic factors, the logistic regression model showed women with incomes below $\$ 50000$ who qualified for enhanced assistance by way of the age of their spouse to have $15 \%$ higher adjusted odds of filling 1 or more prescription for antihypertensive drug than women who did not qualify for enhanced assistance (adjusted OR $1.15,95 \%$ CI 1.06 to 1.24$)$. Women with incomes below $\$ 50000$ who qualified for enhanced assistance had 13\% higher adjusted odds of filling 1 or more prescription for cholesterol drugs than women who did not (adjusted OR 1.13, $95 \% \mathrm{CI}=1.06$ to 1.21$)$.

Among women with incomes above \$50 000, enhanced Fair PharmaCare assistance did not have a significant effect on the odds of filling 1 or more prescription for antihypertensive drugs. Women with incomes above $\$ 50000$ who qualified for enhanced assistance by way of the age of their spouses had $8 \%$ higher adjusted odds of filling 1 or more prescription for cholesterol drugs than women who did not qualify for enhanced assistance (adjusted OR 1.08, 95\% CI 1.01 to 1.15).

Enhanced assistance under the Fair PharmaCare program had no significant effects on the mean duration of treatment purchased by participants who filled 1 or more prescription for antihypertensive or cholesterol drugs.

\section{Interpretation}

Using a natural experiment by way of public drug plan design in British Columbia, we found lower deductibles under an income-based drug benefit program to be associated with increased access to cardiovascular medications. In models that adjusted for patient age, general health status, drug-specific diagnoses, ethnicity, place of residence and household income, for women with household incomes under $\$ 50000$ (42\% of our study population), having lower deductibles under the Fair PharmaCare program in British Columbia was associated with a $15 \%$ increase in the odds of filling 1 or more prescription for hypertension treatment in 2013 and a 13\% increase in the odds of filling 1 or more prescription for cholesterol treatments.

Our findings concerning the effects of health status, age and ethnicity were consistent with previous research on medication use among the more general population in British Columbia. ${ }^{22-24}$ Our findings concerning the effects of Fair PharmaCare deductibles on access to cardiovascular treatments are consistent with earlier studies of the drug plan in British Columbia. Those studies found that the implementation of income-based deductibles for older residents' drug coverage reduced the use of statins and $\beta$ blockers (a hypertension drug class). ${ }^{8,9}$
We found that lower deductibles by way of enhanced assistance under the Fair PharmaCare program had little effect on the quantity of treatments purchased among patients filling 1 or more prescription for the cardiovascular drug classes studied. This finding is inconsistent with studies showing that comprehensive drug coverage improves persistence with prescribed therapies following index prescriptions. ${ }^{25} \mathrm{We}$ note, however, that the effect of cost-related nonadherence is likely to appear in our exposure statistics rather than quantity measures. This is because only a fraction of the patients in our period prevalence exposure measures (i.e., those filling 1 or more prescription for medications in 2013) would have been truly incident users in that year. Most patients identified as users of medicines in our study would have started therapy before 2013. Those who started treatment in previous years and then stopped treatment soon after initiation because of cost do not show up in our data as "low-quantity users," but rather as "nonusers."

\section{Limitations}

The natural experiment used in this study has advantages insofar as the means of qualifying for enhanced coverage in British Columbia - spousal age - was independent of health needs, income levels or other factors that would clearly be related to medication accessibility. In addition, our study drew on population-based administrative data sets that capture a substantial amount of health and sociodemographic information about each participant. This study is not without drawbacks, however. First, developing comparable cohorts of enhanced versus standard benefits recipients required that we focus on a narrow age range of a specific demographic subgroup: married women born between 1940 and 1944. Our findings for the older married women in this study may not generalize to men, unmarried women or younger populations. Furthermore, the limited sample sizes resulting from our study design resulted in relatively wide CIs and made it infeasible to use index events (such as heart attack) to measure differences in treatment initiation and subsequent persistence.

The administrative data used in this study do not contain details, such as disease severity, that are important determinants of prescription decision-making. This potential weakness is attenuated by the mechanism by which policy rules assigned our study participants to enhanced versus standard coverage for medications, based on a personal characteristic that is unlikely to be correlated with unobserved confounding. Income and health status differences were present in our study cohorts; yet, these differences likely stemmed, in part, from differences in mean patient age between the cohorts. Differences in income were also likely driven, in part, by difference in spousal ages (and, therefore, likelihood that spouses were still working) across the cohorts. There were also ethnic differences in our cohorts, which may have arisen from cultural norms concerning the mean age difference between spouses for the generation of women in our sample. ${ }^{21}$ After controlling for age, income and ethnicity in our regression analyses, it is unlikely that remaining differences in the adjusted odds of treatment exposure found in our study were a result of unobserved confounding. 
Finally, the government of British Columbia does not collect data on whether citizens have private insurance for drug costs below the deductibles set under the public drug plan. Our study assessed usage patterns as a function of benefit levels 10 years after the initial implementation of income-based deductibles for public coverage of medicines used by older British Columbians. By that time, many people who could access private drug coverage through their employers may have done so. The unmeasured existence of voluntary private insurance is an unobserved confounding factor that may bias our results toward the null hypothesis of no difference in drug use between groups. This is because the control group of women in our study - those with standard assistance under the Fair PharmaCare system - comprised women and were more likely to have private insurance. This is because our control group included women who were themselves slightly younger than the enhanced intervention group and because they had to be married to younger spouses. As a consequence, the control group lived in households more likely to have a full-time worker in 2013 and, therefore, more likely to have access to employer-provided private insurance in $2013 .{ }^{3}$

\section{Conclusion}

We have found that the level of income-based deductibles under catastrophic drug benefit plans can affect the use of cardiovascular drug treatments, even long after deductibles are put in place. The results of this study therefore add to the body of evidence in support of the idea that public drug coverage designs should limit the costs to patients for treatments that are essential to the maintenance of good health. ${ }^{25,26}$

\section{References}

1. Morgan SG, Barer M, Agnew J. Whither seniors' pharmacare: lessons from (and for) Canada. Health Aff (Millwood) 2003;22:49-59.

2. Morgan SG, Daw JR, Law M. Are income-based public drug benefit programs fit for an aging population? Montréal: The Institute for Research in Public Policy; 2014.

3. Barnes S, Anderson L. Low earnings, unfilled prescriptions: employer-provided health benefit coverage in Canada. Toronto: Wellesley Institute; 2015.

4. B.C.'s Fair PharmaCare Program. In: Backgrounder: Improvements under Fair PharmaCare. Vancouver: British Columbia Ministry of Health Services; 2003. Available: https://archive.news.gov.bc.ca/releases/archive/20012005/2003HSER0013-000192-Attachment1.htm (accessed 2017 Mar. 2).

5. Daw JR, Morgan SG. Stitching the gaps in the Canadian public drug coverage patchwork? A review of provincial pharmacare policy changes from 2000 to 2010. Health Policy 2012;104:19-26.

6. Morgan S, Coombes M. Income-based drug coverage in British Columbia: toward an understanding of the policy. Healthc Policy 2006;2:92-108.

7. Dormuth CR, Glynn RJ, Neumann P, et al. Impact of two sequential drug cost-sharing policies on the use of inhaled medications in older patients with chronic obstructive pulmonary disease or asthma. Clin Ther 2006;28:964-78.

8. Schneeweiss S, Patrick AR, Maclure M, et al. Adherence to statin therapy under drug cost sharing in patients with and without acute myocardial infarction: a population-based natural experiment. Circulation 2007;115:2128-35.

9. Schneeweiss S, Patrick AR, Maclure M, et al. Adherence to beta-blocker therapy under drug cost-sharing in patients with and without acute myocardial infarction. Am 7 Manag Care 2007;13:445-52.
10. Wang PS, Patrick AR, Dormuth CR, et al. The impact of cost sharing on antidepressant use among older adults in British Columbia. Psychiatr Serv 2008;59:377-83.

11. Law MR, Cheng L, Dhalla IA, et al. The effect of cost on adherence to prescription medications in Canada. CMA7 2012;184:297-302.

12. Prescription drug access and affordability an issue for nearly a quarter of all Canadian bousebolds. Vancouver: Angus Reid Institute;2015.

13. Canadian Institute for Health Information. Discharge Abstracts Database (Hospital separations file). Vancouver: Population Data BC. Data Extract. MOH; 2014. Available: www.popdata.bc.ca/data (accessed 2017 Feb. 28).

14. BC Ministry of Health. Medical Services Plan (MSP) Payment information file Vancouver: Population Data BC. Data Extract. MOH; 2014. Available: www. popdata.bc.ca/data (accessed 2017 Feb. 28)

15. PharmaNet. Vancouver: BC Ministry of Health. Data Extract. Data Stewardship Committee; 2014. Available: www.popdata.bc.ca/data (accessed 2017 Feb. 28).

16. Hanley GE, Morgan S, Reid RJ. Explaining prescription drug use and expenditures using the adjusted clinical groups case-mix system in the population of British Columbia, Canada. Med Care 2010;48:402-8.

17. Hanley GE, Morgan S. On the validity of area-based income measures to proxy household income. BMC Health Serv Res 2008;8:79.

18. Leong VW, Morgan S, Wong S, et al. Registration for public drug benefits across areas of differing ethnic composition in British Columbia, Canada. BMC Health Serv Res 2010;10:171.

19. Shah BR, Chiu M, Amin S, et al. Surname lists to identify South Asian and Chinese ethnicity from secondary data in Ontario, Canada: a validation study. BMC Med Res Methodol 2010;10:42.

20. The diversity of visible minorities and ethnic origins in $B C$. Victoria: Ministry of Attorney General and Minister Responsible for Multiculturalism; 2008.

21. Boyd M, Li A. May-December: Canadians in age-discrepant relationships. Can Soc Trends 2003; autumn:29-33.

22. Smolina K, Ball L, Humphries KH, et al. Sex disparities in post-acute myocardial infarction pharmacologic treatment initiation and adherence: problem for young women. Circ Cardiovasc Qual Outcomes 2015;8:586-92.

23. Morgan S, Hanley G, Cunningham C, et al. Ethnic differences in the use of prescription drugs: a cross-sectional analysis of linked survey and administrative data. Open Med 2011;5:e87-93.

24. Morgan SG, Weymann D, Pratt B, et al. Sex differences in the risk of receiving potentially inappropriate prescriptions among older adults. Age Ageing 2016;45:535-42.

25. Adams AS, Soumerai SB, Ross-Degnan D. The case for a medicare drug coverage benefit: a critical review of the empirical evidence. Annu Rev Public Health 2001;22:49-61.

26. Kesselheim AS, Huybrechts KF, Choudhry NK, et al. Prescription drug insurance coverage and patient health outcomes: a systematic review. $A m \mathfrak{F}$ Public Health 2015;105:e17-30.

Affiliations: School of Population and Public Health, Faculty of Medicine (Morgan), University of British Columbia; School of Population and Public Health, Faculty of Medicine (Gladstone), University of British Columbia; Canadian Centre for Applied Research in Cancer Control (Weymann), British Columbia Cancer Agency; Division of General Internal Medicine, Faculty of Medicine (Khan), University of British Columbia, Vancouver, BC

Contributors: Steven Morgan is responsible for study concept and design, interpretation of results and drafting of the manuscript. Emilie Gladstone and Deirdre Weymann assisted with study design, analysis of data, interpretation of results and revising the manuscript for important intellectual content. Nadia Khan assisted with study design, interpretation of results and revising the manuscript for important intellectual content. All of the authors approved the final version to be published and agreed to act as guarantors of the work.

Funding: This work was supported in part by the Canadian Institutes of Health Research (CIHR DCO150GP). The funding agency had no role in the study or decision to publish. All opinions and conclusions are those of the authors.

Supplemental information: For reviewer comments and the original submission of this manuscript, please see www.cmajopen.ca/content/5/1/ E198/suppl/DC1 